\title{
Political micro-targeting: a Manchurian candidate or just a dark horse?
}

\section{Balázs Bodó}

Institute for Information Law, University of Amsterdam, Amsterdam, Netherlands, bodo@uva.nl

\author{
Natali Helberger \\ Institute for Information Law (IViR), University of Amsterdam, Amsterdam, Netherlands
}

\section{Claes H. de Vreese}

Department of Communication Science, University of Amsterdam, Amsterdam, Netherlands

Published on 30 Dec 2017 | DOI: 10.14763/2017.4.776

\begin{abstract}
Political micro-targeting (PMT) has become a popular topic both in academia and in the public discussions after the surprise results of the 2016 US presidential election, the UK vote on leaving the European Union, and a number of general elections in Europe in 2017. Yet, we still know little about whether PMT is a tool with such destructive potential that it requires close societal control, or if it's "just" a new phenomenon with currently unknown capacities, but which can ultimately be incorporated into our political processes. In this article we identify the points where we think we need to further develop our analytical capacities around PMT. We argue that we need to decouple research from the US context, and through more non-US and comparative research we need to develop a better understanding of the macro, meso, and micro level factors that affect the adoption and success of PMTs across different countries. One of the most under-researched macro-level factors is law. We argue that PMT research must develop a better understanding of law, especially in Europe, where the regulatory frameworks around platforms, personal data, political and commercial speech do shape the use and effectiveness of PMT. We point out that the incorporation of such new factors calls for the sophistication of research designs, which currently rely too much on qualitative methods, and use too little of the data that exists on PMT. And finally, we call for distancing PMT research from the hype surrounding the new PMT capabilities, and the moral panics that quickly develop around its uses.
\end{abstract}

Keywords: Political micro-targeting, Democracy 


\section{Article information}

Received: 20 Dec 2017 Reviewed: 25 Dec 2017 Published: 30 Dec 2017

Licence: Creative Commons Attribution 3.0 Germany

Competing interests: The author has declared that no competing interests exist that have influenced

the text.

URL:

http://policyreview.info/articles/analysis/political-micro-targeting-manchurian-candidate-or-just-dark-

horse

\section{PAPERS IN THIS SPECIAL ISSUE}

Political micro-targeting: A Manchurian candidate or just a dark horse? Towards the next generation of political micro-targeting research

Balázs Bodó, Natali Helberger, \& Claes H. de Vreese, University of Amsterdam

The role of digital marketing in political campaigns

Jeff Chester, Center for Digital Democracy

Kathryn C. Montgomery, American University

WhatsApp in Brazil: mobilising voters through door-to-door and personal messages

Mauricio Moura, The George Washington University

Melissa R. Michelson, Menlo College

Two crates of beer and 40 pizzas: the adoption of innovative political behavioural targeting techniques

Tom Dobber, Damian Trilling, Natali Helberger, \& Claes H. de Vreese, University of Amsterdam

\section{Restrictions on data-driven political micro-targeting in Germany}

Simon Kruschinski, Johannes Gutenberg University Mainz

André Haller, University of Mainz

On democracy

Sophie in 't Veld, European Parliament

Micro-targeting, the quantified persuasion

Daniel Kreiss, University of North Carolina at Chapel Hill 


\section{POLITICAL MICRO-TARGETING: A MANCHURIAN CANDIDATE OR JUST A DARK HORSE? TOWARDS THE NEXT GENERATION OF POLITICAL MICRO-TARGETING RESEARCH}

\section{IT IS TIME TO TAKE A CRITICAL LOOK AT POLITICAL MICRO-TARGETING}

Political targeting is not a new phenomenon. Political parties, candidates, and campaigns have a long history of classifying and segmenting the 'voter market' in order to optimise their messages to different profiles. Political micro-targeting (PMT), however, only became prominent in recent election cycles. PMT refers to the use of different communications (mail, phone, canvassing, direct mail, and social media advertising, etc.) to communicate and build a relationship with prospective voters. At the core of the concept is the use of data and analytics to craft and convey a tailored message to a subgroup or individual members of the electorate. The 2008 US presidential elections was the first major election that perfected micro-targeting models, by, for example, using information about voters to direct volunteers to 'scripted conversations with specific voters at the door or over the phone' (Issenberg, 2012).

The popular myth about PMT is, that it is about voter persuasion. Of course, it be used towards the 'ultimate' goal of influencing candidate and party preferences and ultimately behaviour, but it would be a mistake to think if this as its only use. PMT can be used to (dis)encourage political participation, including election turnout. It can (dis)encourage donations and contributions to candidates and campaigns. It can be employed to create energy and interest in a campaign, election and candidate, but it can also be used to create disinterest and apathy.

In the past decade, the reference to and discussion of PMT has increased. The most significant public discussion took place in the aftermath of the 2016 US presidential elections. As the public realised the full scope of PMT possibilities, the public debates and news coverage of targeted ads on Facebook, the use of algorithms and foreign funding, and the centrality of data analytics companies led to moral panic, congressional hearings, and the quest for more transparency and understanding of this particular election, and PMT more generally.

At the end of 2017 we have the UK, French, German and Dutch elections behind us, and the Italian one before us. All these elections used one type of PMT or another, marking the point in time, when the PMT techniques developed in the highly innovative and liberal (i.e. underregulated) US context are being adopted to all kinds of political systems across Europe, and ultimately, across the globe. The task of scrutinising the use and impact of PMT techniques on local elections and political systems in Europe could not be more timely.

\section{TENSIONS IN RESEARCH}

Given the historical development of PMT and today's uncertainties about the prevalence, impact, and possible lack of regulation of PMT, it becomes important to highlight some of the tensions and inconsistencies in current thinking about the phenomenon. There is a whole range of issues that research needs to address in order to properly grasp PMT, such as how new (or old) the phenomenon really is, whether it represents more of an opportunity than a threat, and finally, whether PMT means the same in different political and regulatory contexts around the 
globe.

\section{HOW MUCH IS NEW, HOW MUCH OLD?}

PMT does not come out of a vacuum. Political advertising and the professionalisation of politics and campaigns have been topics of investigation for decades. On the one hand it is tempting to consider PMT a natural evolution of developing practices in campaigning and advertising. On the other hand, PMT coincides with other fast-paced and almost disruptive developments. PMT is not just a change in approach and methods, it also speaks to a change of institutions. As the campaign spending shifts from billboards, broadcast, and print to online, social, and data, so do the institutions that connect and separate parties and politicians to/from the electorate change (see also Montgomery and Chester in this special issue). These institutions, online media platforms, data brokers, technology providers, analytics companies are perhaps the most novel aspect of today's PMT compared to other aspects which are more organically evolving aspects of campaigning, data usage, and advertising in general.

As the research on PMT matures it is becoming a relevant question whether PMT is solely an election phenomenon. In the burgeoning literature on how politics and campaigns professionalized in the 1980s and 1990s, it became apparent that some of these developments apply not only to election time, but also to governing (Cook, 2005). Holding an office today does not mean a full electoral cycle break away from monitoring, interacting with and nudging constituencies (Csigó, 2017). In the same vein, PMT can conceivably be used in interesting ways to be part of government communication and thereby unfold not only as a feature of campaigning but also of governing.

\section{RISKS VS OPPORTUNITIES: UTOPIAN VS DYSTOPIAN PERSPECTIVES}

The most important opportunities offered by political micro-targeting techniques coincide with the promises of digital advertising. Digital technologies offer more data points to profile individual consumers by. Digital communication channels offer more precise targeting. Taken together, better profiling and better targeting are hoped to provide consumers (voters) with more relevant information, with which they are more likely to engage. Political advertisers, mainly political parties, hope to get more efficient and effective services out those same technologies, for a fraction of the cost. Lower costs and more efficient targeting in turn could lower the entry barriers to the political communication market for smaller parties, and enable parties with limited resources or with a more specific message to reach out to constituents.

All things considered these benefits may lead to a more diverse political marketplace in terms of products and sellers, i.e., issues, parties, candidates; and better informed, more conscious political consumers making better informed political choices. (Borgesius et al., forthcoming)

Some of the risks associated with PMT also mirror concerns raised in the commercial advertising domain: profiling entails a loss of user privacy, targeting opens the door for selective information exposure, and potential manipulation (Bennett, 2015). Political parties, who have to deal with the new, digital intermediaries often in exclusive control of access to voters, may face monopoly prices, and experience a loss of power. Taken together these buyer and seller effects may result in the fragmentation of the marketplace (of ideas), and make it costly for the consumers (voters) to be sufficiently informed about the true nature of the available supply (of ideas, and candidates) on the political marketplace (Borgesius et al., forthcoming).

Yet, at the end of 2017, it seems that the greatest concrete threats of PMT were not what an analogy with commercial advertising would have suggested. First, as we discuss it in more detail 
in the next section, it seems that different rules apply to commercial and political advertising. While both in the US, the UK and in the EU sophisticated regulatory frameworks protect consumers from false, and misleading commercial advertisements, political speech is not judged by the same standards. As a result, negative advertisement, smear campaigns and the like are often widely used strategies in campaigns (Johnson-Cartee \& Copeland, 2013). Second, as it has been realised too late in the 2016 US presidential elections, and just in time in the French one, local political parties are not the only ones to see PMT as an effective tool to influence the outcome of elections. PMT techniques were used by foreign state actors, independent nongovernmental organisations, and entrepreneurial individuals alike to take advantage of an election process in various ways. Balkan teens were found to exploit the heated US campaign by spreading fake news for commercial gains (Subramanian, 2017); the independent tech libertarian organisation Wikileaks had a substantial impact on multiple elections, with its sometimes curiously timed releases of confidential information (Bodó, 2014); while the Russian meddling with political events from the 2016 US presidential elections via the 2017 French elections to the current tensions around Catalonia is currently under heavy scrutiny by both local security services and global publics (Director of National Intelligence, 2017; Emmott, 2017; Greenberg, 2017). Third, to make things worse, the intransparency of PMT techniques makes it close to impossible to detect and fully assess such activities.

Finally, it is increasingly apparent the interests of digital intermediaries who enable PMT techniques are not necessarily aligned with the interests of voters, political parties, or the interests of society at large (Caplan, 2016). Such a conflict of interest of the commercial arbitrators of political speech was first described by Robert McChesney (1999) in the context of the US commercial broadcast media. He suggested that the fact that commercial media rather sees political speech in the form of revenue generating ad than a cost-generating news programme is detrimental to democracy. This conflict of interest is especially true for digital intermediaries, most of whom do not produce any content in the first place. There is no guaranteed "organic reach" for even those civil movements, causes, organisations, political parties, political candidates, activists, who otherwise successfully nurture large and well managed online communities; serious news media need to pay if they want to reach audiences, so there is no "public service", commercially disinterested, non-profit marketplace for political speech on digital intermediaries (Madrigal, 2017; Wagner, 2017). All political audiences are ultimately sold to the highest bidder.

In other words, the biggest opportunity of PMT is also its biggest threat: sophisticated technologies allow anyone to reach any individual or group in an electorate with any message. Moreover, this access is on commercial terms, and on commercial terms only, where the audiences are sold to the highest bidder, without any regard to wider, societal concerns, such as the protection of voters from fraud; a diverse, balanced and competitive marketplace of ideas; a well-informed citizenry; or a level playing field for political parties.

\section{CONTEXT VS CONDITIONS: LEGAL FRAMEWORKS MATTER}

Political campaigning and the electoral system are at the heart of the democratic process. Ensuring the fairness, transparency, and openness of this process is paramount to its success. Accordingly, democratic societies have a long tradition of devising rules and procedures to guide political campaigning and political advertising, with the goal of promoting and defending democratic values and fundamental rights in this very process. In Europe, the the Council of Europe's Venice Commission - with representatives from 60 countries - in 2002 established five fundamental electoral principles, including "universal, equal, free, secret and direct suffrage" principles that have guided the way national governments design and enable their electoral 
systems, including the way political advertising is regulated.

Political advertising is protected speech in the sense of Art. 10 ECHR (European Court of Human Rights, VgT Verein gegen Tierfabriken v. Switzerland), and citizens have the right to inform themselves and receive political information from a diversity of sources and perspectives. Council of Europe member states are under the obligation to enable "free elections at reasonable intervals by secret ballot, under conditions which will ensure the free expression of the opinion of the people in the choice of the legislature." (Article 3 of Protocol No. 1 to the European Convention on Human Rights). This obligation has resulted in rules on various aspects of political campaigning in general, and political advertising specifically.

So far much of the legal debates around political advertising have concentrated on the scope and affordances of data protection law (Bennet, 2016). Data protection law, however, can only go so far to protect principles of universality, equality or freedom of the political, data-driven process. In other words: data protection law is no 'all purpose tool', equipped to deal with all challenges of political micro-targeting, simply because they deal with data. Instead, it is high time to include other legal areas into the discussion, and their role in addressing the effects from data analytics, including election, party financing laws, and media law.

With regard to political advertising, one set of rules that is particularly relevant are the rules about party financing that must ensure transparency and fairness in the way parties receive and spend public and private money to fund their (advertising) campaigns (Anstaed and Chadwick, 2016). In response to the use of PMT in the UK Brexit campaign, these provisions stood central in an investigation of the UK Electoral Commission into the extent to which the divestitures in PMT were potentially in conflict with the British rules on campaign financing. Political advertising is also subject to a battery of rules in national media laws - rules that determine meticulously the way in which political parties may or may not advertise on the (traditional) media (many national broadcasting law issue a ban in principle on political advertising in broadcasting), who has to be granted how much advertising time, and what are the limits and who exercises oversight (for an overview, see Apa et al. 2017).

These rules were written for the traditional mass media, and media campaigning. They apply to the broadcasting media, not to platforms, as new central players in political advertising. The challenge is to transport the provisions about equality and fairness, transparency and oversight to the new digital realities of PMT, as well as to the new central players: digital platforms, but also data brokers and analytics firms. The discussion about the regulation of PMT on platforms is part of a broader discussion about the social responsibility of platforms, and the extent to which we can oblige large commercial Silicon Valley companies to observe democratic values, such as media diversity, fairness and equality in the democratic process. It is clear and established that the public service media and newspapers have an important task in providing a platform for the diverse encounters of ideas and opinions. The role and public responsibility of platforms still needs to be carved out. Platforms have come to play a central role in gathering information and forming (political) opinions. They have also become part of the mission-critical campaign infrastructure, next to the traditional media. And yet, many of these platforms are driven by an advertising business model, and from their perspective as advertising companies, political micro-targeting is 'just' another form of advertising. And current laws, e-commerce law do little to correct that assumption. PMT is another example that shows that the discrepancy in current regulation between demanding responsible behaviour from the offline media, and providing maximum leeway and 'room to play' for the online media as the 'youngest kid' in the family, is no longer tenable. Online media, and platforms in particular, have grown up, and it is 
high time to create more similar standards across different media and different forms of advertising, and more guidance on 'fair targeting practices'.

For the past decade, a central ambition of regulatory reforms in the area of data protection law but also consumer law sought to create a fairer level playing field for the commercial sister of political advertising: behavioural targeting (BT). Similarly to PMT, behavioural targeting seeks to utilise data-driven insights into consumer preferences and characteristics to optimise advertising, make it more personally relevant, efficient and persuasive. Regulatory reforms in the European General Data Protection Regulation (GDPR) must give consumers more information and control rights vis-à-vis data-driven advertisers. As outlined in a symposium 1 contribution by Maximilian von Grafenstein and Jessica Schmeiss, the provisions in the European General Data Protection Regulation apply to the collection, processing of personal data in general (irrespective of whether this is done for purposes of commercial or political targeting), as well as to the use of such data to target users with personalised messages. Insofar, data protection law affords consumers and voters a comparable level of protection in terms of the collection and use of their personal data.

This is different for the protection from false and misleading claims. Here, the European Commission addressed in its latest guidance on the Unfair Commercial Practice Directive a range of potentially unfair forms of behavioural targeting; and the ongoing reform of European consumer law must afford more protection to consumers in the digital marketplace. False, misleading or aggressive advertising claims are banned under the provisions of Unfair Commercial Practices. These rules apply to commercial communication, but not necessarily to ideological advertising (also depending on the country in question).

The recent debate about the obligation of platforms to disclose political advertising, too, is from the perspective of consumer law, nothing new under the sun: the obligation to label commercial advertising messages and disclose sponsored content is an iron rule in advertising law and unfair commercial practice law. For political micro-targeting on social networks, such obligations are in many countries still missing, or just about to be drafted.

In other words, many of the rules that must guarantee informed and autonomous decision making in the light of behavioural targeting do not apply to ideological advertising. Similarly, while the commercial advertising industry has developed since long codes of conduct and instances to guard over the fairness and truth in advertising, including digital advertising, such self-regulatory initiatives in the field of political advertising still need to be developed. The question is by whom? Political parties? Platforms? Analytics companies such as Cambridge Analytica? Fairness, truthfulness and transparency are arguably important values, also in the relationship between voters and political parties.

Behavioural and political micro-targeting use essentially the same technologies, sometimes even the same data. And yet we face in Europe the puzzling situation that the trust of consumers in the truthfulness and fairness of commercial behavioural advertising seems to be better protected than that of citizens that are the recipients of political micro-targeting. A critical challenge for the law, and legal scholars in the years to come will be to even out this inadequate and undemocratic imbalance in protection, and devise principles and rules about Unfair Political Practices.

In this context, it can be useful to learn from the diversity of emerging (self)regulatory approaches and experimentations with new solutions in the European Union member states. For example, the Dutch "Social Media Advertising Code" (Reclamecode Social Media) 2 does 
address surreptitious political advertising through social media and requires, among others, disclosure of any payment social media users receive for the distribution of advertising messages. In the UK, the Electoral Commission has begun to develop guidance on the rules applicable to online media. In Ireland, the Data Protection Commissioner issued guidelines to candidates for election, and their representatives, on canvassing, data protection and electronic marketing for the General Election in 2016,3 as well as guidance on the use of electronic media for political direct marketing under the principles developed for the regulation for spam. All these are examples for initiatives that seek to develop guidance, either through self-regulation or issued by the regulator, and that have started to carve out principles of fairness in political micro-targeting vis-à-vis voters.

\section{THEORY VS PRACTICE}

The advance of digital technologies and the subsequent uncertainties unleashed a period of moral panics among academics as well as social commentators. There is a strong market for both "TED-talk-sized utopian visions", and the most dystopian doomsday scenarios of political deception, fragmentation and the ultimate collapse of democracies.

Comparing such speculations with the campaigns and elections until the end of 2017 proved that speculation and the actual practices on the ground were rarely in line. As outlined by the piece on the 2017 Dutch national elections by Tom Dobber et al., or on the 2017 German federal elections by Simon Kruschinski and André Haller a number of practical limitations, such as the lack of expertise, funds or real demand; the particularities of the local jurisdiction; or the political and media systems tend to moderate the theoretically expected (positive or negative) impact of PMT. On the other hand, few, if any theoretical models managed to foresee what turned out to be the greatest threat of not only PMT, but of digital platforms and intermediaries in general, namely that bad faith (state) actors do possess the resources and the incentives to weaponise digital communication platforms, and in times of elections PMTs, and turn them into highly disruptive tools of information warfare (Maréchal, 2016; Patrikarakos, 2017, Powers, 2010).

One might ponder, whether this unexpected turn of events will actually be beneficial in mitigating the worst theoretically predicted threats of PMT and enable us to exploit the opportunities it offers in a more systematic and orderly manner. Threats, such as the aforementioned Russian interference in the 2016 US presidential elections via social media suddenly turned PMT techniques into the most closely watched domains, where everyone, from the media via congressional committees to national security services seemed to be ready to monitor and regulate this space. One can only hope that under such intense scrutiny the more ordinary threats envisioned by theory will have less chance to turn into reality.

We also have to be aware that much of the literature on the opportunities, threats and the actual use of PMT originates in the US. The reasons for that are obvious: US political campaigners have been developing PMT techniques since the early 200os. Yet, as more than one contribution in this issue suggests, the PMT practices developed in the US do not enjoy universal appeal or success in other countries. As we discussed above, there are many factors that affect the applicability and effectiveness of particular PMT techniques, from the size of campaign budgets, via data protection rules, to the modalities of the political and media systems. As studies on actual PMT applications start to emerge from Brazil to Germany, it is high time to consider what parts of the US based theoretical discourse is applicable beyond the borders of the US political sphere. It would be a mistake to treat the US experience with PMT as a point each country will unavoidably pass in its teleological development of PMT-driven political communication. 
Instead, future research should carefully assess which of the opportunities and threats are the product of the particular, and rather exceptional US political, social, economic, cultural conditions, and what are the barriers in front of the global transfer of PMT practices, positive or negative effects, actors, knowledge, etc.

\section{MOVING BEYOND THE STATE OF PLAY: THE NEXT GENERATION OF POLITICAL MICRO-TARGETING RESEARCH}

Research on PMT is burgeoning. Put bluntly, PMT research suffers from an overdose of US perspectives, an underdose of European, South American, Asian perspectives, a too heavy reliance on interview data, and too much of mono-theoretical paradigms.

As outlined above there are good reasons why the US perspective is so dominant: many industry based developments are spearheaded in the US, the US electoral advertising industry is large and advanced, and the US has databases such as voter registration files which are game changers in terms of PMT. However, these very characteristics also make it problematic that so much of our knowledge is based in this single case. Most other western democracies (to allow for some comparative benchmark) have much smaller political advertising industries (limited by generally more modest campaign budgets), different political, electoral and media systems, and less accessible voter databases. This means that non-US studies, in particular comparative ones, are needed as the field moves forward so as to avoid basing our collective knowledge on a case which is exceptional (and thus abnormal) on many parameters.

Extant PMT research also suffers from heavy reliance on one type of studies. Whereas other areas of political communication research undoubtedly suffer from a strong reliance on content analyses, survey data or experimentation, the study of campaign techniques and the use of PMT relies too heavily on interview data. Such data are very informative and useful but typically reveal less information about the distribution of PMT, its usage, or let alone its effects. This is important since much of the public debate centers on assumptions about usage and effects. The prevalence of qualitative approaches is especially limiting because PMT could easily lend itself to big data based quantitative research methods. Having access to such datasets is an issue, and researchers should advocate transparency rules that enable such research (Bodo et al., 2017), but as a number of studies have proven, such quantitative approaches are not just feasible, but also shed light to phenomena invisible to qualitative methods (Puschmann, 2017).

Current PMT research also suffers from mono-theoretical blindness. Oftentimes the understanding and investigation of PMT provides only an overview of regulations, or focuses only on campaign practices or big data analytics. Too rarely are studies integrated such that different theoretical concepts, disciplines, and designs converge around answering PMT-related questions.

\section{IN THIS ISSUE}

This collection of papers comes out of the Personalised Communication project $_{4}$ - an interdisciplinary project currently underway at the University of Amsterdam. It is the result of an international call for proposals, and subsequent international symposium held in Amsterdam 
on 22 September 2017. The symposium had the explicit aim of bringing researchers together from different disciplines and different political and media systems, all with an interest in PMT.

As we outlined above, we consider research PMT of eminent importance. On the one hand global players, such as digital platforms, agencies, consultants developed PMT based products and services in the US market, which they are now offering across the globe. On the other hand, there are more and more willing buyers among local politicians and parties, who are glad to test if PMT is able to deliver at least a fraction of its promised results. As the use of PMTs is slowly becoming the new normal in political communication, it is also pertinent that we, as scholars develop and refine the appropriate theories, research methods, and frames in which we can study PMT across different territories, jurisdictions, media and political systems, and compare our findings, before making bold claims about the effects and normative implications of PMT.

This special issue does not alleviate all of these potential concerns about PMT, and the research environment around PMT driven practices. Nevertheless, this selection of studies does offer bigger diversity of cases and foci. Most empirical papers are cognizant about regulatory and normative implications and vice versa. And while the prominence of interview based findings is not combatted in this issue either, papers rely on a wide variety of data.

The special issue includes four peer reviewed articles. They touch on broader industry regulations, and offer case studies and insights from diverse jurisdictions such as Brazil, Germany and the Netherlands. At the end of the special issue we include an abbreviated version of a speech delivered by MEP Sophie in 't Veld to Data \& Democracy, a conference on political micro-targeting held in Amsterdam in May 2017, as well as a reflection by renowned political communication scholar and expert on political micro-targeting, Daniel Kreiss.

Jeff Chester and Kathryn Montgomery provide a much needed in depth insight into the current state of the industry that services political micro-targeting efforts in the US. Even if in a few years none of the firms mentioned in this article would remain, we believe we need a thorough overview of the state of play, the stakeholders and their claims, as they stood in late 2017, after the double, and rather unexpected shock of the surprise election of Donald Trump (in 2016!) and the vote for UK's exit of the European Union (June 2016!).

Mauricio Moura and Melissa Michelson's empirical study on the effectiveness of different mobilisation efforts in Brazil serves as a useful reminder of why and how we should not take whatever we learn from the US experiences for granted. Due to its unregulated nature Whatsapp played a central role in the general elections in Brazil. Moura and Michelson's study suggests that it has a strong impact when it comes to its ability to mobilise voters. Their study also reminds us that digital intermediaries can be used as a mass media as much as a personalised media.

Tom Dobber, Damian Trilling, Natali Helberger and Claes de Vreese's account on the use of PMT techniques during the 2017 Dutch general elections highlights the fundamental differences between how PMT is regarded and used in the US and another, technologically and economically highly developed, but European country. To explain the strikingly lower appeal of PMT in the Netherlands, Dobber et al. make the first steps to outline the theoretical framework in which all factors that might affect local PMT applicability can be situated and assessed against each other.

Simon Kruchinski and André Haller look at use of PMT in the canvassing efforts of German parties during the 2016 state parliament elections in Rhineland-Palatinate. The authors 
introduce a framework of macro-, meso-, and micro level constraints that define the use, and usefulness of various PMT techniques in different countries. Using in-depth interviews they then identify the limited German parties' use of PMT. They suggest that besides system-level, contextual factors such as budgetary restraints, and strict legal rules on data protection and privacy, the meso-, and micro level factors, such as the party structures and campaign knowledge, are also have a strong impact on the usefulness of micro-targeting.

At last, we invited two contributions from two leading voices on political micro-targeting. Daniel Kreiss is the leading scholar on the use PMT in the US political system. Sophie in 't Veld is a Dutch politician, Member of the European Parliament for Democrats 66, a Dutch liberal party. Their respective texts have the common concern for the future of democracy, in an era dominated by unchecked commercial influence over the political communication process, foreign meddling, and unaccountable, intransparent digital middlemen. But the differences between their perspectives, and analysis is as important as their shared anxieties, as they reflect the particular social, economic, political conditions in which these texts were born.

Kreiss sees PMT as a technology that reflects, reinforces and amplifies the partisan conflicts at the heart of US politics, the political agonism, the clash of competing social groups, interests, and values in the binary US political sphere. For him, the loss of the theoretical ideal of a rational debate between well informed citizens due to PMT is not much relevant in the context of the ideological war between the two opposing US parties. In t' Veld, on the other hand, comes from the Netherlands, where 13 different parties make up the national parliament, another dozen are present in local legislatures, and works in the European Parliament where seven different party groups exist. For her, the deliberative aspects of democracy, and the negative effects PMT might have on those, are in the forefront.

The two closing opinions and the five peer reviewed studies are all based on a shared concern for democracy. Their differences in methods, topics, coverage and angle highlight the diversity of not just the issues at hand, but the much needed diversity of voices, this PMT research needs, if we are to understand the role of political micro-targeting in our democracies. 


\section{REFERENCES}

Anstead, N., \& Chadwick, A. J. (2009). Parties, election campaigning, and the Internet: toward a comparative institutional approach. In A. J. Chadwick \& P. N. Howard (Eds.), Routledge handbook of internet politics (pp. 56-71). London: Routledge.

Apa, E., Bassini, M., Bruna, A., Blázquez, F. J. C., Cunningham, I., Etteldorf, C., ... Rozendaal, M. (2017). Media coverage of elections: the legal framework in Europe (IRIS Special). (F. Courrèges, M. P. Sarl, N. Sturlèse, S. Pooth, E. Rohwer, \& S. Schmidt, Trans.). Strasbourg: European Audiovisual Observatory. Retrieved from http://www.obs.coe.int/documents/205595/8714633/IRIS+Special+2017-1+Media+coverage+ of+elections+-+the+legal+framework+in+Europe.pdf

Bennett, C. J. (2015). Trends in voter surveillance in western societies: privacy intrusions and democratic implications. Surveillance \& Society, 13(3/4), 370-384. Retrieved from:

https://ojs.library.queensu.ca/index.php/surveillance-and-society/article/view/voter_surv

Bennet, C. J. (2016). Voter databases, micro-targeting, and data protection law: can political parties campaign in Europe as they do in North America? International Data Privacy Law, 6(4), 261-275. doi:10.1093/idpl/ipwo21

Balázs, B. (2014). Hacktivism 1-2-3: How Privacy Enhancing Technologies Change the Face of Anonymous Hacktivism. Internet Policy Review, 3(4). doi:10.14763/2014.4.340

Bodo, B., Helberger, N., Irion, K., Zuiderveen Borgesius, F., Möller, J., van de Velde, B., Bol, N., van Es, B., \& de Vreese, C. (2017). Tackling the Algorithmic Control Crisis - The Technical, Legal, and Ethical Challenges of Research into Algorithmic Agents. Yale Journal of Law and Technology, 19, 133-180. Retrieved from:

http://yjolt.org/tackling-algorithmic-control-crisis-technical-legal-and-ethical-challenges-resea rch-algorithmic

Zuiderveen Borgesius, F. J., Möller, J., Kruikemeier, S., Fathaigh, R. Ó., Irion, K., T. Dobber, T., Bodo, B., \& de Vreese, C. . Online Political Microtargeting: Promises and Threats for Democracy. Utrecht Law Review. Forthcoming.

Caplan, R. (2016, November 22). Facebook Must Acknowledge and Change Its Financial Incentives. The New York Times. Retrieved from

https://www.nytimes.com/roomfordebate/2016/11/22/how-to-stop-the-spread-of-fake-news/f acebook-must-acknowledge-and-change-its-financial-incentives

Csigó, P. (2016). The neopopular bubble: speculating on "the people" in late modern democracy. Budapest; New York: Central European University Press.

Director of National Intelligence. 2017. Background to "Assessing Russian Activities and Intentions in Recent US Elections": The Analytic Process and Cyber Incident Attribution. Washington, DC: Office of The Director of National Intelligence

Emmot, R. (2017, November 13). Spain sees Russian interference in Catalonia separatist vote. Reuters. Retrieved from https://www.reuters.com/article/us-spain-politics-cataloniarussia/spain-sees-russian-interference-in-catalonia-separatist-vote-idUSKBN1DD2OY

Greenberg, A. (2017, May 9). NSA Director Confirms That Russia Really Did Hack the French 
Election. Wired. Retrieved from https://www.wired.com/2017/05/nsa-director-confirmsrussia-hacked-french-election-infrastructure/

Johnson-Cartee, K. S., \& Copeland, G. (2013). Negative political advertising: Coming of age. Routledge.

Madrigal, A. C. (2017, October 24). When the Facebook Traffic Goes Away. The Atlantic. Retrieved from https://www.theatlantic.com/technology/archive/2017/10/when-thefacebook-traffic-goes-away/543828/

Maréchal, N. (2016). Automation, Algorithms, and Politics | When Bots Tweet: Toward a Normative Framework for Bots on Social Networking Sites (Feature). International Journal of Communication, 10, 10. Retrieved from: http://ijoc.org/index.php/ijoc/article/view/6180

McChesney, R. W. (1999). Rich media, poor democracy: communication politics in dubious times. Urbana: University of Illinois Press.

Parliamentary Assembly of the Council of Europe Resolution 2143 (2017). Online media and journalism: challenges and accountability. Retrieved from:

http://assembly.coe.int/nw/xml/XRef/Xref-DocDetails-EN.asp?FileID=23455\&lang=2

Patrikarakos, D. 2017. War in 140 characters : how social media is reshaping conflict in the twenty-first century. New York: Basic Books.

Powers, S. 2010. Weaponized Media, Legitimacy and the Fourth Estate: A Comment. Ethnopolitics, 9(2), 255-258. doi:10.1080/17449051003764855

Puschmann, C. (2017, August 2). How significant is algorithmic personalization in searches for political parties and candidates? Retrieved from https://aps.hans-bredowinstitut.de/personalization-google/

Subramanian, S. (2017). Inside the Macedonian Fake-News Complex. Wired Magazine, 15. Retrieved from https://www.wired.com/2017/02/veles-macedonia-fake-news/

Wagner, K. (2017). Publishers might have to start paying Facebook if they want anyone to see their stories Facebook's latest test should terrify publishers. RECODE. Retrieved from https://www.recode.net/2017/10/23/16525192/facebook-explore-feed-newsmedia-audience-reach-traffic-test

\section{FOOTNOTES}

1. Symposium on Political micro-targeting held in Amsterdam on 22 September 2017.

2. Stichting Reclame Code, Reclamecode Social Media (RSM)

https://www.reclamecode.nl/nrc/pagina.asp?paginaID=289\%20\&deel=2

3. https://www.dataprotection.ie/docimages/documents/DPCanvasGuide.pdf

4. For more information on the research project, please visit www.personalised-communication.net 